Gut, 1978, 19, 632-639

\title{
Role of neural influences in the release of gastrin, glucagon, and secretin during hypoglycaemia in man
}

\author{
J. C. Mcloughlin, J. R. HAYES, K. D. BUChANAN, AND J. G. KELly \\ From the Departments of Medicine and Therapeutics and Pharmacology, Queen's University of Belfast, \\ Belfast
}

SUMMARY Both vagal and sympathetic innervation been have described as influencing hormone release from the gastrointestinal tract and pancreas. The role of neural influences on the release of gastrin, glucagon, and secretin has been studied using the potent autonomic nerve stimulus of hypoglycaemia. Healthy subjects were each rendered hypoglycaemic by insulin 0.2 units/kg on three occasions: after atropine $20 \mu \mathrm{g} / \mathrm{kg}$ : after propranolol $160 \mathrm{mg}$ orally, and without prior drug administration. Adequate beta-blockade was confirmed by observation of the pulse rate response to a standard exercise at the end of the experiment, and by measurement of plasma propranolol levels. Hypoglycaemia failed to produce a rise in plasma gastrin under either propranolol or control conditions but a significant rise was noted with prior atropinisation. The glucagon response to hypoglycaemia, when measured with either the $\mathrm{C}$ - or $\mathrm{N}$-terminal reactive antibodies, was found not to be influenced to any significant extent by either beta-blockade or atropinisation. No alteration in plasma secretin levels was noted during hypoglycaemia. It therefore appears that neural influences are relatively unimportant in the release of gastrin, glucagon, and secretin in man.

Neural control of gastrin release has been the subject of much investigation. Sham-feeding causes release of gastrin in man (Mayer et al., 1974) and animals (Nilsson et al., 1972) but the mechanism is unclear. In dogs a gastrin-releasing mechanism under cholinergic control (Csendes et al., 1972; Nilsson et al., 1972) has been demonstrated. In humans, however, most workers show raised plasma gastrin after vagotomy (Korman et al., 1972; Jaffe et al., 1974), implying impaired inhibition of release. Gastrin stimulation by catecholamines has been described both in man (Hayes et al., 1972; Stadil and Rehfeld, 1973) and in dogs (Hayes et al., 1972). Adrenergic stimulation seems to be the likely mechanism of the rise in plasma gastrin during hypoglycaemia (Stadil and Rehfeld, 1972), as this is not blocked by vagotomy (Stadil, 1972), and is enhanced by atropine (Farooq and Walsh, 1975).

The role of neural influences on glucagon release in vivo remains unclear. While sympathetic nerve stimulation in calves (Bloom et al., 1973) has been

Received for publication 17 August 1977 shown to cause release of glucagon, impairment of glucagon release by atropine in calves (Bloom et al., 1974a) and in man (Bloom et al., 1974b) has also been demonstrated. In vitro studies have demonstrated release of glucagon both by cholinergic (Iversen, 1973a) and adrenergic (Iversen, 1973b) mechanisms.

We are unaware of any work relating to the response of secretin to hypoglycaemia, although some evidence of a cholinergic mechanism in secretin release has been shown (O'Connor et al., 1976). We have used hypoglycaemia as a stimulus to the autonomic nervous system and attempted to characterise the mechanism of a possible response by use of cholinergic and beta adrenergic blocking agents.

\section{Methods}

Six healthy subjects (five male, one female) were each studied on three occasions with an interval of one week between experiments. Their ages ranged from 23 to 32 years (mean 28.6 years) and none had a history of gastrointestinal or metabolic disease. 
After an overnight fast a nasogastric tube was positioned fluoroscopically with the tip at the junction of the body and antrum of the stomach. The subject was then instructed to lie on his left side for the duration of the experiment. Residual gastric juice was aspirated and mechanical suction applied, with additional manual aspiration at least every 15 minutes. Samples were collected for 15 minute intervals. Hypoglycaemia was induced by intravenous soluble insulin (Wellcome B.P.) $\mathbf{0 \cdot 2}$ units $/ \mathbf{k g}$.

On one occasion each subject was given an intravenous injection of atropine $20 \mu \mathrm{g} / \mathrm{kg}$ bodyweight 30 minutes before insulin and on a second occasion a similar volume of saline. On the other occasion each subject was instructed to take propranolol $160 \mathrm{mg}$ (Inderal, ICI) $1 \frac{1}{2}$ hours before the experiment started.

The pulse rate was recorded at 15 minute intervals during the experiment. At 120 minutes after insulin, the nasogastric tube was withdrawn and each subject ate a light snack and rested for 20 minutes. He then performed a standard exercise consisting of stepping on and off a fixed platform 32 times in one minute. The platform height was $45 \mathrm{~cm}$ for the males and $32 \mathrm{~cm}$ for the female subject. The pulse rate was measured before, immediately after, and again at two minutes and five minutes after the exercise.

Blood samples were withdrawn from a forearm vein through a no. 19 Butterfly cannula at -30 , $-15,0,15,30,45,60,75,90,105$, and 120 minutes, flushing the cannula with normal saline after each sample. Blood for hormone estimation was collected in heparinised tubes in melting ice.

Centrifugation and plasma separation at $4{ }^{\circ} \mathrm{C}$ was performed at the end of the experiment. Plasma for gastrin estimation was stored frozen at $-20^{\circ} \mathrm{C}$, whereas plasma for glucagon and secretin estimation was extracted by the method of Heding (1971). Plasma glucose levels were measured by the Neocuproine method (Brown, 1961) using an autoanalyser. The volume of gastric juice in each 15 minute sample was recorded and $5 \mathrm{ml}$ aliquots titrated to $\mathrm{pH} 7.0$ using $0.1 \mathrm{M} \mathrm{NaOH}$ in an automatic titrator with a glass electrode (Radiometer, Copenhagen).

Plasma gastrin levels were measured using a sensitive and specific radioimmunoassay (Ardill, 1973), the assay antibody having been raised in rabbits against synthetic human gastrin 17-1, yet also recognising larger molecular weight forms of immunoreactive gastrin as well as the heptadecapeptide.

Extracts of samples for assay of glucagon and secretin were reconstituted before radioimmunoassay in phosphate buffer pH 7.4 0.04 M. Glucagon was assayed by the method of Buchanan (1973), using two antisera of different specificity-namely, antibody YY89 which reacts with C-terminal sequences and YY57 which reacts with $\mathrm{N}$-terminal sequences of glucagon. The $\mathrm{N}$-terminal reactive antibody measures all known species of glucagon-like immunoreactivity (GLI) in tissues, whereas the C-terminal reactive antibody does not react with most species of GLI in the gut and is, therefore, more specific for pancreatic glucagon. The antibodies are defined as measuring N-terminal reactive GLI (N-GLI) and C-terminal reactive GLI (C-GLI) respectively.

The radioimmunoassay for secretin used the method of Buchanan et al. (1973), with the modification that labelled hormone and standards used synthetic secretin prepared by $\mathrm{Dr}$ E. Wunsch, Max-Planck Institute, Munich.

Blood for plasma propranolol levels was withdrawn at $0,30,60$, and 120 minutes on the appropriate day and assayed by a fluorimetric method (Shand et al., 1970).

Statistical significance of differences was calculated using the paired $t$ test.

\section{Results}

Plasma Glu Cose (Fig. 1)

The degree of hypoglycaemia recorded in all three sets of experiments was similar with no significant difference in the plasma glucose nadir between the groups. However, the rise in plasma glucose over the recovery period of 30 to 120 minutes was significantly impaired under the propranolol conditions $(0.82$ $\pm 0.44 \mathrm{mmol} / \mathrm{l})$ as opposed to the control situation $(1.75 \pm 0.32 \mathrm{mmol} / 1, \mathrm{P}<0.025)$. The rise in plasma glucose was not significantly affected by atropine $(1.59 \pm 0.30 \mathrm{mmol} / \mathrm{l})$.

\section{GASTRIN (Fig. 2)}

No significant rise was found in plasma gastrin levels during insulin hypoglycaemia under control conditions. Likewise no significant rise was found after treatment with propranolol. Atropine intravenously produced no significant change in fasting plasma gastrin concentration but a significant rise was noted at 45 minutes $(P<0.025)$ and 75 minutes $(P<0.0125)$ after insulin (Fig. 3). These points are also significantly different from corresponding points in the control situation ( $P<0.05,<0.025$ respectively).

GLUCAGON (C-GLI Fig. 3; N-GLI Fig. 4)

No significant change in fasting plasma glucagon levels was produced by either atropine or propranolol administration when measured with either 


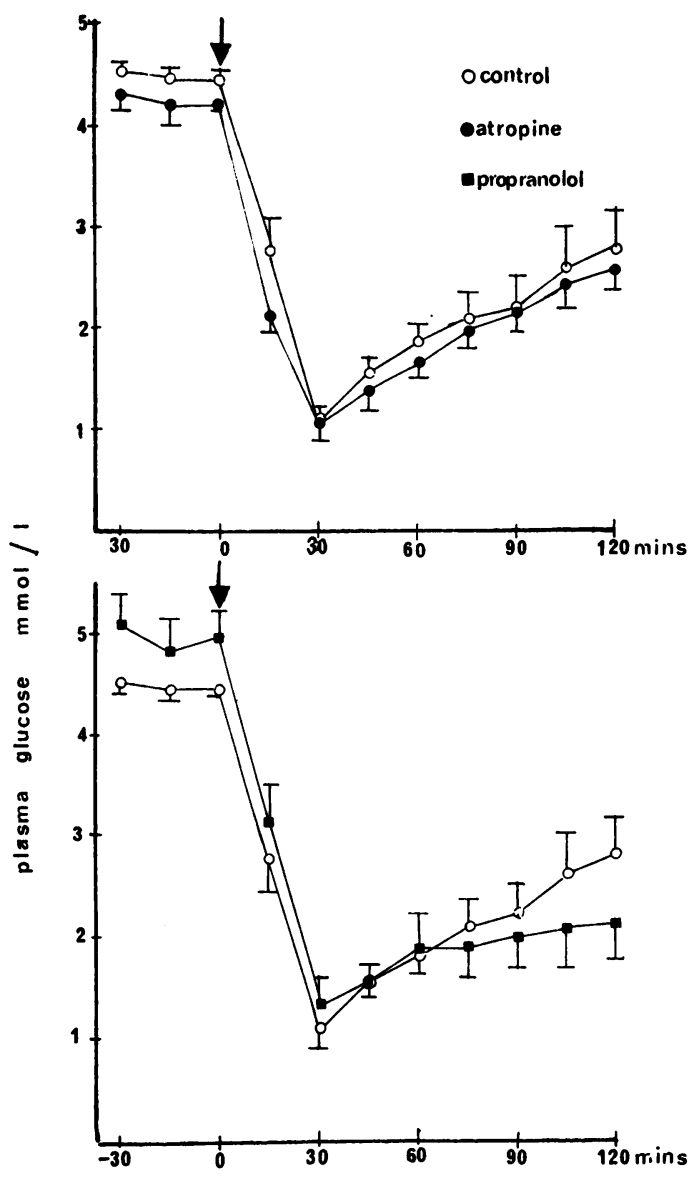

Fig. 1 Plasma sugar during three sets of conditions shown. Insulin $0 \cdot 2$ units $/ \mathrm{kg}$ administered intravenously (arrowed).

C- or N-terminal reactive antibodies. Insulin hypoglycaemia produced a significant rise in both C-GLI and N-GLI. The peak concentration of C-GLI occurred at 45 minutes $(P<0.0025)$ and of $\mathrm{N}-\mathrm{GLI}$ at 75 minutes $(\mathrm{P}<0.05)$. The rise in glucagon was not inhibited by either atropine or propranolol. During hypoglycaemia preceded by propranolol, however, plasma glucagon levels were higher towards the end of the experiment but this may be a feature of the persisting hypoglycaemia.

SECRETIN (Fig. 5)

Plasma secretin levels remained unaltered during hypoglycaemia both under control conditions and when atropine or propranolol had been administered beforehand.

PROPRANOLOL (Fig. 6)

In all subjects, plasma propranolol concentrations

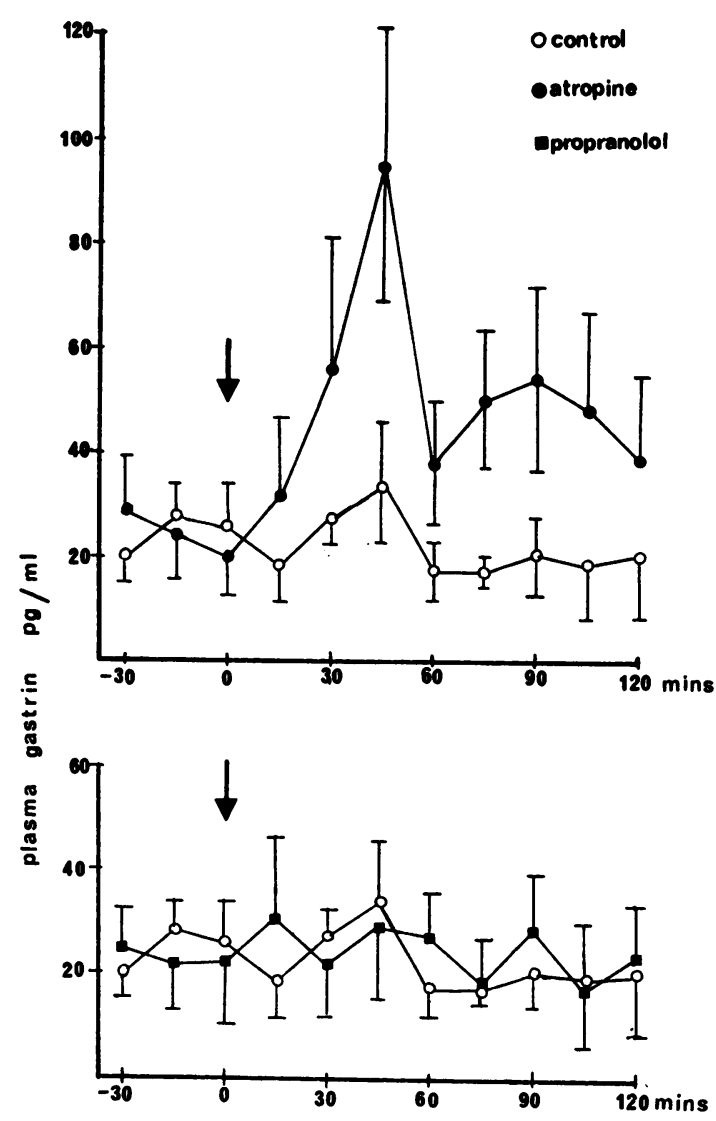

Fig. 2 Plasma gastrin during hypoglycaemia (insulin at arrow).

achieved levels previously described as producing significant antagonism of beta-adrenergic receptors after its oral administration (Chidsey et al., 1976). In five of the subjects the lowest concentration observed was $180 \mathrm{ng} / \mathrm{ml}$ at 60 minutes. In the remaining subject the minimum concentration observed was $65 \mathrm{ng} / \mathrm{ml}$ also at 60 minutes.

PULSE RATE (Fig. 7)

Observations of the pulse rate before and after the standard exercise (Fig. 7, lower diagram) demonstrates that the degree of atropinisation and betablockade remained significant at the end of the experiment. The pulse rate under control conditions differed significantly from atropine and propranolol conditions respectively before $(\mathrm{P}<0.0005, \mathrm{P}<$ $0.025)$, immediately after $(\mathrm{P}<0.0025, \mathrm{P}<0.0025)$, and five minutes after $(\mathrm{P}<0.05, \mathrm{P}<0.0025)$ the standard exercise. The rise in pulse rate induced by the exercise was similar in both the control $(65.0$ \pm 6.1 beats $/ \mathrm{min})$ and atropinised state $(66.5$ 


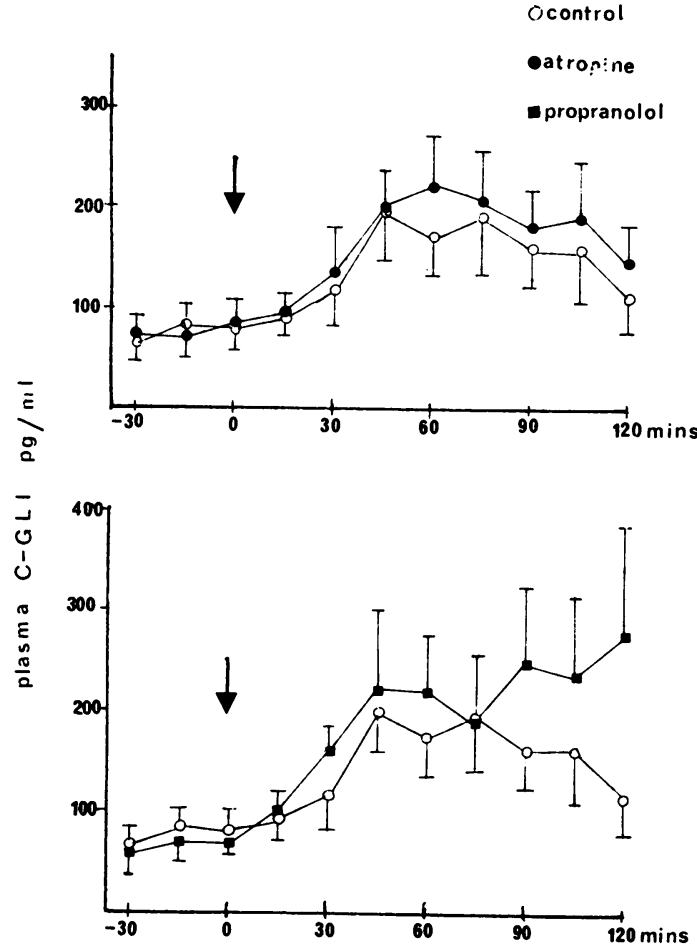

Fig. 3 Plasma C-terminal glucagon-like immunoreactivity (C-GLI) after insulin (arrowed).

\pm 4.8 beats $/ \mathrm{min})$ but was halved $(32.0 \pm 3.2$ beats/min) by propranolol.

During hypoglycaemia, a significant rise in pulse rate was noted at both the 30 minute $(\mathrm{P}<0.0005)$ and 45 minute $(\mathrm{P}<0.025)$ observations (Fig. 7, upper diagram) which was blocked by propranolol and therefore likely to be due to sympathetic activity. The significant fall in pulse rate under propranolol conditions, first noted at 45 minutes $(P<0.01)$ but persisting till the end of the experiment, occurred at a time when plasma propranolol levels were falling (Fig. 6).

GASTRIC ACID (Fig. 8)

The acid output in each 15 minute interval is shown in Fig. 7. Under control conditions acid production reached a peak of $6.50 \pm 1.00 \mathrm{mmol}$ in the $45-60$ minute specimen (mean $\pm \mathrm{SEM}$ ). With prior administration of atropine, acid production was significantly lower in all post-insulin specimens except in the 60-75 minute sample. Significant acid inhibition by atropine therefore persisted until the end of the experiment.

After propranolol the pattern of acid response appeared to be altered with a significant difference

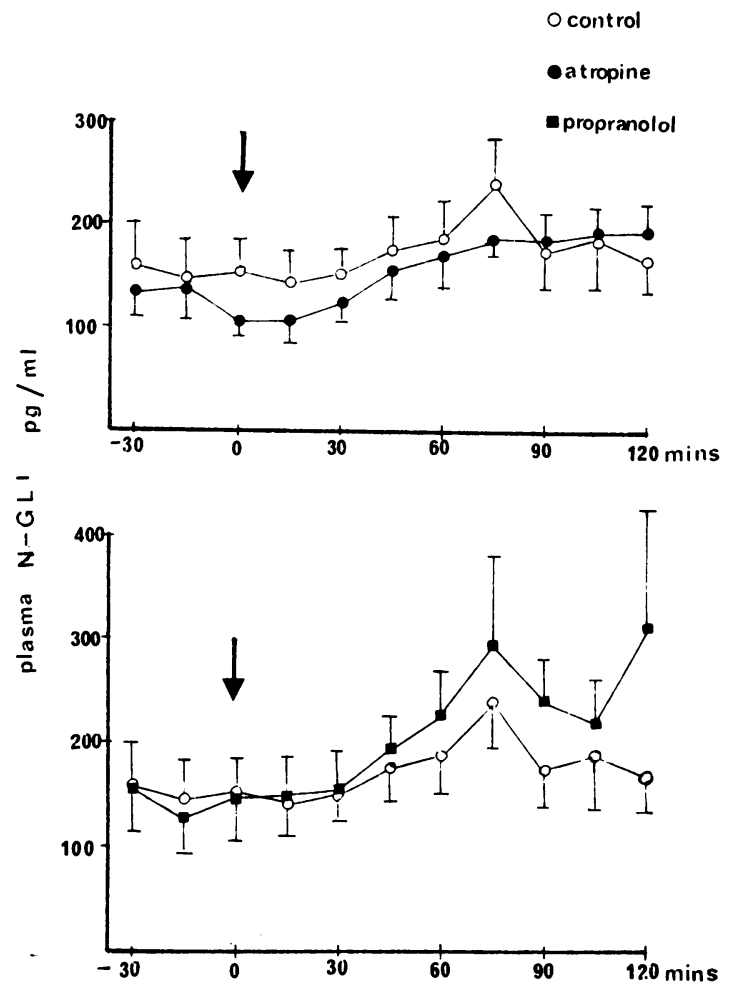

Fig. 4 Plasma N-GLI after insulin (arrowed).

in the acid output being recorded in the $45-60$ minute period.

\section{Discussion}

The plasma glucose nadir was similar under all three sets of conditions. Recovery from hypoglycaemia was not impaired by atropine, so that we may regard the autonomic stimulus as similar on both occasions. The delay in plasma glucose recovery under beta-blockade, however, renders more difficult the direct comparison of results with the control. This phenomenon is well recognised (Abramson et al., 1966) and is shared by other beta-blocking agents which are supposedly cardioselective (Newman, 1976). Catecholamines therefore play a large part in recovery from hypoglycaemia and there is evidence that their effect is not solely caused by beta-adrenergic activity.

Plasma propranolol levels recorded were consistent with those described as producing significant antagonism of beta-adrenergic receptors (Chidsey et al., 1976). Adequate beta-blockade was also demonstrated by pulse rate observations before and after the standard exercise. At the end of 

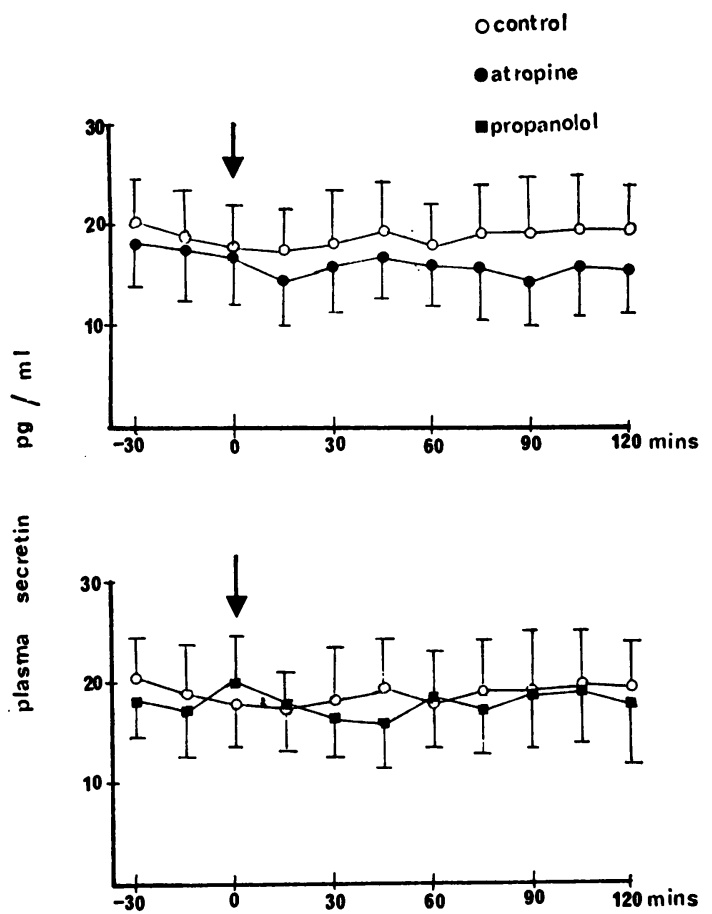

Fig. 5 Plasma secretin during insulin (arrowed)induced hypoglycaemia.

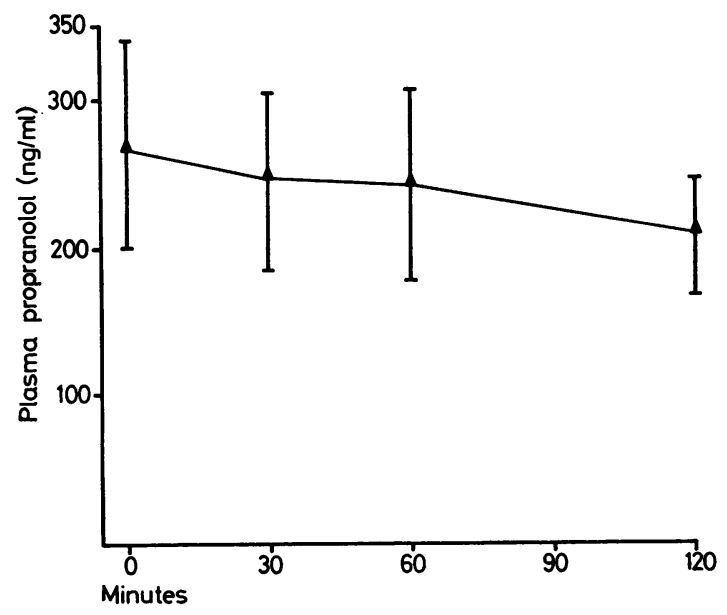

Fig. 6 Plasma propranolol levels.

the experiment, both the pulse rate and gastric acid production were significantly lower under atropinisation, demonstrating that significant cholinergic blockade remained at this time.

The rise in pulse rate first noted at 30 minutes in the control experiment was blocked by pro-

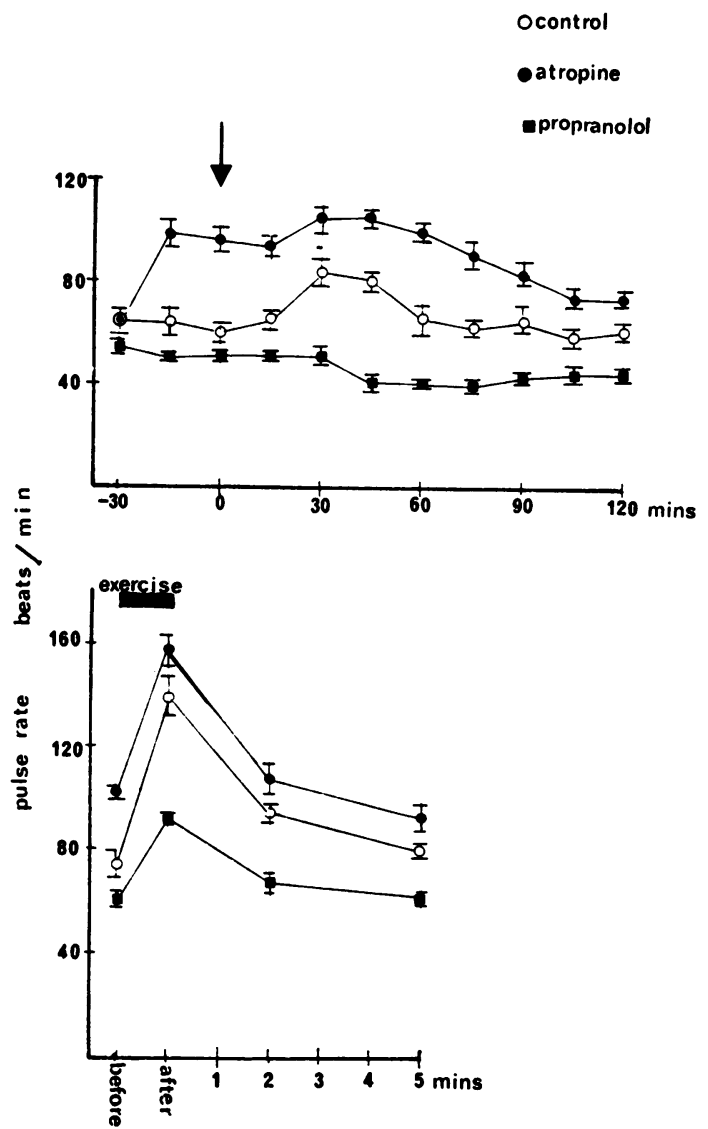

Fig. 7 (Top) Pulse rate response to insulin-induced hypoglycaemia. Atropine given at -30 minutes (see text). (Bottom) Pulse rate response to standard exercise (see text).

pranolol but also reduced by atropine. This would suggest that it is mainly related to sympathetic activity but perhaps partially to a reduction in vagal activity. The fall in pulse rate under propranolol conditions, occurring between 30 and 45 minutes, was at a time when plasma propranolol levels were falling and was therefore likely to be related to increased vagal tone. This time is similar to that of the onset of acid secretion during hypoglycaemia (Fig. 8).

These simple observations demonstrate that the onset of vagal stimulation in hypoglycaemia occurs later than that of sympathetic activity and that both thoracic and abdominal fibres in the vagus are involved.

The delay in acid response to hypoglycaemia found with beta-blockade is rather confusing. While the result may be spurious and related to 


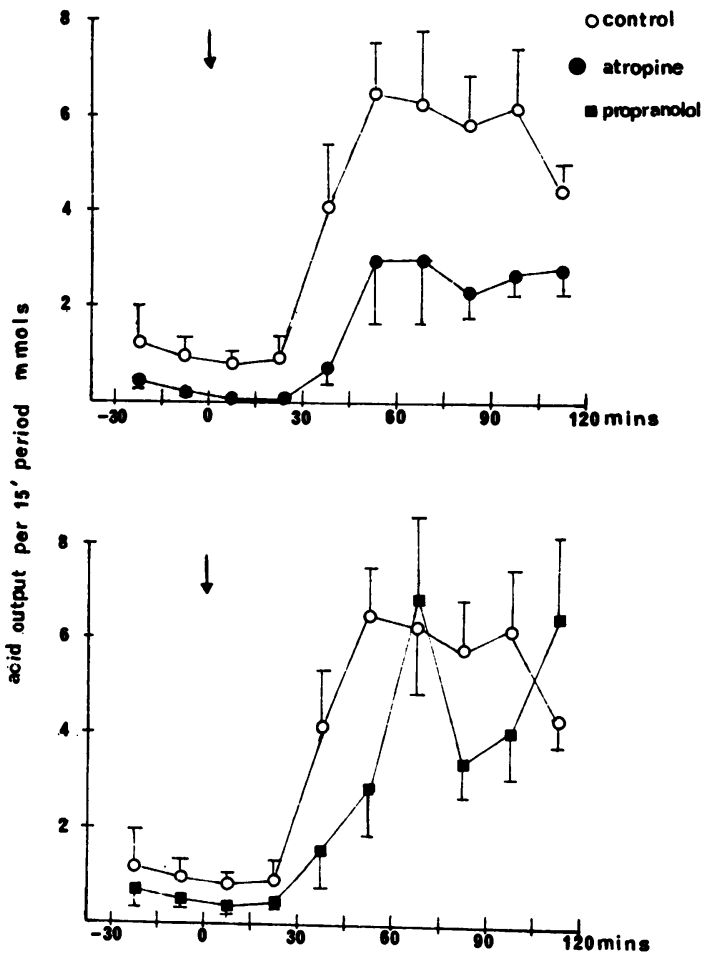

Fig. 8 Acid output per 15 minute period after insulin (arrowed).

difficulties with acid collection, it is possible that beta-adrenergic fibres play some part in the acid response in the early stages of hypoglycaemia.

No clear rise in plasma gastrin has been shown to occur under control conditions in the six normal subjects investigated in this study. This is in keeping with others who have found a non-significant (Korman et al., 1971; Berson and Yalow, 1972) or a small rise (Stadil and Rehfeld, 1974) in normal subjects, yet a clear response in duodenal ulcer subjects (Cowley et al., 1972; Stadil and Rehfeld, 1972).

The clear rise shown here during hypoglycaemia preceded by atropine is similar to the findings of Farooq and Walsh (1975) and supports that of others who have found that vagotomy (Stadil, 1972; Hall et al., 1973) or vagal cooling (Cairns et al., 1974) did not inhibit the gastrin response. We cannot totally exclude, however, that the enhanced gastrin response may be related to a lesser degree of acidinhibition of gastrin release found after atropine.

These findings are very different from shamfeeding experiments in dogs (Nilsson et al., 1972), where atropine was found to block the rise in gastrin. While species difference may account for this, a further possible explanation is that the vagus contains fibres both to enhance and inhibit gastrin release. Both may be cholinergic, as suggested by Debas et al. (1976), although electric stimulation of the vagus under atropinisation still causes gastrin release in dogs (Smith et al., 1975). Stimulation of gastrin release by the vagus may therefore be under the influence of the adrenergic vagal fibres found in many species-including man (Lundberg et al., 1976).

In this study we have been unable to alter the glucagon response to hypoglycaemia by either cholinergic or beta adrenergic blockade. In the latter circumstances, the delayed rebound of plasma sugar renders comparison difficult. Bloom et al. (1974b) demonstrated a diminished glucagon response to hypoglycaemia in a group of post-truncal vagotomy subjects, yet the response was normal in a post-selective vagotomy group where pancreatic innervation is preserved. No delay in glucagon response was noted, a feature previously described in calves during hypoglycaemia under the influence of atropine (Bloom et al., 1974a).

Other evidence of vagal involvement in glucagon release is the partial blockade by atropine of the glucagon rise associated with arginine infusion in humans (Bloom et al., 1974b). In vitro experiments have demonstrated glucagon release both by acetylcholine (Iversen, 1973a) and adrenergic agents (Iversen, 1973b). Stimulation of pancreatic sympathetic innervation in calves (Bloom et al., 1973) and in dogs (Kaneto et al., 1975) has also effected glucagon release. In the latter case propranolol or phentolomine failed to block the response. In other animals there are conflicting reports of alpha (Tyler and Kajinuma, 1972) and beta (Luyckx and Lefebvre, 1972) adrenergic mediation of glucagon release. Infusion of adrenaline into humans produced a rise of immunoreactive glucagon levels in blood which was blocked by alpha adrenergic blockade (Gerich et al., 1972), yet, when hypoglycaemia was used as a stimulus in man, the glucagon response was unaffected by either alpha or beta blocking agents. Using beta adrenergic and cholinergic blockade in this study we likewise were unable to inhibit glucagon release. It may be that hypoglycaemia is such a potent glucagon stimulant that it overrides neural control of glucagon release. In this study alpha blockade was not attempted, so that alpha adrenergic stimulation remains a possible contender, either through direct islet innervation or by circulating catecholamines which increase tenfold during hypoglycaemia (Vendsalu, 1960). Reconciliation of these results with post-vagotomy findings above (Bloom et al., 1974b) can be effected only if the catecholamine- 
containing fibres in the human vagus (Lundberg et al., 1976) are responsible for glucagon release.

The role of glucagon in assisting recovery of plasma sugar levels is probably a minor one, as beta-blockade reduced the rate of recovery by half, despite the fact that glucagon release was uninhibited. In addition, there is evidence that the hyperglycaemic effect of catecholamines is not solely mediated through beta receptors (Antonis et al., 1967).

A neural component of secretin release has been previously postulated (Moreland and Johnson, 1971; O'Connor et al., 1976). Henriksen et al. (1976) described a urecholine-stimulated change in $\mathrm{pH}$ threshold for its release in dogs. Ward and Bloom (1975), however, did not record any change in the secretin response to intraduodenal acid after vagotomy in humans. Using the potent autonomic nerve stimulus of hypoglycaemia, we have found no alteration in plasma secretin levels. While autonomic stimulation may possibly prime the duodenum for acid-stimulated secretin release, this study suggests that secretin is neither stimulated nor inhibited directly by cholinergic or beta-adrenergic influences.

\section{References}

Abramson, E. A., Arky, R. A., and Woeber, K. A. (1966). Effects of propranolol on the hormonal and metabolic responses to insulin induced hypoglycaemia. Lancet, 2, 1386-1389.

Antonis, A., Clark, M. L., Hodge, R. L., Molony, M., and Pilkington, T. R. E. (1967). Receptor mechanisms in the hyperglycaemic response to adrenaline in man. Lancet, 1, 1135-1137.

Ardill, J. E. S. (1973). The Measurement of Gastrin by Radioimmunoassay. Ph.D. thesis: Queen's University of Belfast.

Berson, S. A., and Yalow, R. S. (1972). Radioimmunoassay in gastroenterology. Gastroenterology, 62, 1061-1084.

Bloom, S. R., Edwards, A. V., and Vaughan, N. J. A. (1973). The role of the sympathetic innervation in the control of plasma glucagon concentration in the calf. Journal of Physiology, 233, 457-466.

Bloom, S. R., Edwards, A. V., and Vaughan, N. J. A. (1974a). The role of the autonomic innervation in the control of glucagon release during hypoglycaemia in the calf. Journal of Physiology, 263, 611-623.

Bloom, S. R., Vaughan, N. J. A., and Russell, R. C. G. (1974b). Vagal control of glucagon release in man. Lancet, 2, 546-549.

Brown, M. E. (1961). Ultra-micro sugar determinations using 2, 9-dimethyl-1, 10-phenanthroline hydrochloride (Neocuproine). Diabetes, 10, 60-62.

Buchanan, K. D., Teale, J. D., Harper, G., Hayes, J. R., and Trimble, E. R. (1973). Plasma secretin assay in man. Clinical Science, 45, 13P-14P.

Buchanan, K. D. (1973). Studies on the Pancreatic-Enteric Hormones. Ph.D. thesis: Queen's University of Belfast.

Cairns, D., Deveney, C. W., and Way, L. W. (1974) Mech. anism of the release of gastrin by insulin hypoglycaemiaSurgical Forum, 25, 325-327.

Chidsey, C., Pine, M., Favrot, L., Smith, S., Leonetti, G., Morselli, P., and Zanchetti, A. (1976). The use of drug concentration measurements in studies of the therapeutic response to propranolol. Postgraduate Medical Journal, 52, Suppl. 4, 26-32.

Cowley, D. J., Baron, J. H., Hansky, J., and Korman, M. G. (1972). Relationships between serum gastrin and gastric acid secretion during insulin hypoglycaemia in normal subjects and in patients with duodenal ulcer. British Journal of Surgery, 59, 305 (Abstract).

Csendes, A., Walsh, J. H., and Grossman, M. I. (1972). Effects of atropine and of antral acidification on gastrin release and acid secretion in response to insulin and feeding in dogs. Gastroenterology, 63, 257-263.

Debas, H. T., Walsh, J. H., and Grossman, M. I. (1976). After vagotomy atropine suppresses gastrin release by food. Gastroenterology, 70, 1082-1084.

Farooq, O., and Walsh, J. H. (1975). Atropine enhances serum gastrin response to insulin in man. Gastroenterology, 68, 662-666.

Flanagan, R. W. J. (Personal communication.) Purification of $\mathrm{I}^{125}$ secretion by ion-exchange chromatography.

Gerich, J. E., Karam, J. H., and Forsham, P. H. (1972). Reciprocal adrenergic control of pancreatic alpha- and beta-cell function (abstract). Diabetes 21, 332-333.

Hall, W. H., Durkin, M. G., and Read, R. C. (1973). Propranolol and serum gastrin in postvagotomy insulin tests. Digestion, 9, 325-331.

Hayes, J. R., Ardill, J., Kennedy, T. L., Shanks, R. G., and Buchanan, K. D. (1972). Stimulation of gastrin release by catecholamines. Lancet, 1, 819-821.

Heding, L. G. (1971). Radioimmunological determination of pancreatic and gut glucagon in plasma. Diabetologia, 7, 10-19.

Henriksen, F. W., Halse, C., and Holm-Bentzen, M. (1976). Cholinergic influence on the canine jejunal pH threshold for secretin release (abstract). Scandinavian Journal of Gastroenterology, 11, suppl. 38, 1 .

Iversen, J. (1973a). Effect of acetylcholine on the secretion of glucagon and insulin from the isolated, perfused canine pancreas. Diabetes, 22, 381-387.

Iversen, J. (1973b). Adrenergic receptors and the secretion of glucagon and insulin from the isolated, perfused canine pancreas. Journal of Clinical Investigation, 52, 2102-2116.

Jaffe, B. M., Clendinnen, B. G., Clarke, R. J., and Williams, J. A. (1974). Effect of selective and proximal gastric vagotomy on serum gastrin. Gastroenterology, 66, 944-953.

Kaneto, A., Kajinuma, H., and Kosaka, K. (1975). Effect of splanchnic nerve stimulation on glucagon and insulin output in the dog. Endocrinology, 96, 143-150.

Korman, M. G., Soveny, C., and Hansky, J. (1971). Radioimmunoassay of gastrin. The response of serum gastrin to insulin hypoglycaemia. Scandinavian Journal of Gastroenterology, 6, 71-75.

Korman, M. G., Hansky, J., and Scott, P. R. (1972). Serum gastrin in duodenal ulcer. III. influence of vagotomy and pylorectomy. Gut, 13, 39-42.

Lundberg, J., Ahlman, H., Dahlström, A., and Kewenter, J. (1976). Catecholamine-containing nerve fibres in the human abdominal vagus. Gastroenterology, 70, 472-474.

Luyckx, A. S., and Lefebvre, P. J. (1972). Role of catecholamines in exercise-induced glucagon secretion in rats. Diabetes, 21, 334. (Abstract.)

Mayer, G., Arnold, R., Feurle, G., Fuchs, K., Ketterer, H., Track, N. S., and Creutzfeldt, W. (1974). Influence of feeding and sham-feeding upon serum gastrin and gastric acid secretion in control subjects and duodenal ulcer patients. Scandinavian Journal of Gastroenterology, 9, 703-710.

Moreland, H. J., and Johnson, L. R. (1971). Effect of vagotomy on pancreatic secretion stimulated by endogenous and exogenous secretin. Gastroenterology, $60,425-431$. 
Newman, R. J. (1976). Comparison of propranolol, metoprolol, and acebutolol on insulin-induced hypoglycaemia. British Medical Journal, 2, 447-449.

Nilsson, G., Simon, J., Yalow, R. S., and Berson, S. A. (1972). Plasma gastrin and gastric acid responses to sham-feeding and feeding in dogs. Gastroenterology, 63, 51-59.

O'Connor, F. A., Buchanan, K. D., Connon, J. J., and Shahidullah, M. (1976). Secretin and insulin: Response to intraduodenal acid. Diabetologia, 12, 145-148.

Shand, D. G., Nuckolls, E. M., and Oates, J. A. (1970). Plasma propranolol levels in adults with observations in four children. Clinical Pharmacology and Therapeutics, 11, 112-120.

Smith, C. L., Kewenter, J., Connell, A. M., Ardill, J., Hayes, J. R., and Buchanan, K. D. (1975). Control factors in the release of gastrin by direct electrical stimulation of the vagus. American Journal of Digestive Diseases, 20, 13-22.

Stadil, F., (1972). Effect of vagotomy on gastrin release during insulin hypoglycaemia in ulcer patients. Scandinavian Journal of Gastroenterology, 7, 225-231.

Stadil, F., and Rehfeld, J. F. (1972). Hypoglycaemic release of gastrin in man. Scandinavian Journal of Gastroenterology, 7, 509-514.

Stadil, F., and Rehfeld, J. F. (1973). Release of gastrin by epinephrine in man. Gastroenterology, 65, 210-215.

Stadil, F., and Rehfeld, J. F. (1974). Effect of insulin injection on serum gastrin concentrations in duodenal ulcer patients and normal subjects. Scandinavian Journal of Gastroenterology, 9, 143-147.

Tyler, J. M., and Kajinuma, H. (1972). Influence of betaadrenergic and cholinergic agents in vivo on pancreatic glucagon and insulin secretion. (Abstract.) Diabetes, $21,332$.

Vendsalu, A. (1960). Studies on adrenaline and nonadrenaline in human plasma. Acta Physiologia Scandinavica, 49, suppl. 173, 1-123.

Ward, A. S., and Bloom, S. R. (1975). Effect of vagotomy on secretin release in man. Gut, 16, 951-956. 